\title{
ESTRATÉGIAS DE VISIBILIDADE EM CONTEXTO PANDÊMICO: O MAPEAMENTO DA PANDEMIA DA COVID-19 ENTRE POVOS INDÍGENAS NO MARANHÃO
}

\author{
ANA CAROLINE AMORIM OLIVEIRA ${ }^{1}$ \\ UFMA, BRASIL \\ https://orcid.org/0000-0002-9337-6335 \\ DAISY DAMASCENO ARAÚJO ${ }^{2}$ \\ IFMA, BRASIL \\ https://orcid.org/0000-0002-6601-1664 \\ KATIA NÚBIA FERREIRA CORRÊA ${ }^{3}$ \\ GPEMPP/UFMA, BRASIL \\ https://orcid.org/0000-0002-7050-7646 \\ RODRIGO THEOPHILO FOLHES ${ }^{4}$ \\ AGERP/MA, BRASIL \\ https://orcid.org/0000-0001-7853-8925
}

\begin{abstract}
RESUMO: Este artigo objetiva apresentar as estratégias de mapeamento, qualificação e visibilidade dos dados da Covid-19 entre os povos indígenas no estado do Maranhão, refletindo sobre os impactos do novo coronavirus na vida destes povos e sobre a realidade de assistência à saúde destinada a eles. A pesquisa possui uma abordagem qualitativa apresentando os resultados do mapeamento realizado de maio a agosto de 2020 e as estratégias metodológicas provocadas pelo contexto pandêmico para o desenvolvimento da pesquisa em meio digital (MILLER, 2020). Tomamos como base quatro fontes de informações estatísticas para a coleta dos dados: os boletins epidemiológicos produzidos nos âmbitos federal, estadual, municipal e as informações disponibilizadas pelas organizações indigenistas e indígenas, nos respectivos sítios eletrônicos. Identificamos inicialmente uma ausência de informações sobre os casos de Covid-19 entre povos indigenas nas fontes oficiais e, quando publicizadas, não contemplavam as especificidades dos povos acometidos pelo vírus, apresentando dados genéricos e generalizados, nos impedindo de compreender a realidade sanitária de forma especifica e diferenciada. Assim, a pandemia se alastrou nos territórios indígenas e as estratégias do governo contribuíram para tal quadro.
\end{abstract}

PALAVRAS-CHAVES: pandemia da covid-19, estratégias metodológicas, povos indígenas, Maranhão.

ABSTRACT: This article aims to present the mapping strategies, qualification and visibility of Covid-19 data among indigenous peoples in the state of Maranhão, reflecting on the impacts of

\footnotetext{
${ }^{1}$ Doutora em Antropologia Social pelo Programa de Pós-Graduação em Antropologia Social da Universidade de São Paulo (USP). E-mail: ana.caroline.oliveira@gmail.com

${ }^{2}$ Doutora em Ciências Sociais pelo Programa de Pós-Graduação em Ciências Sociais da Universidade Federal do Maranhão (PPGCSOC/UFMA). E-mail: daisy.araujo@ifma.edu.br

${ }^{3}$ Doutora em Ciências Sociais pelo Programa de Pós-Graduação em Ciências Sociais da Universidade Federal do Maranhão (PPGCSOC/UFMA). E-mail: knubiaf@gmail.com

${ }^{4}$ Doutor em Ciências Sociais pelo Programa de Pós-Graduação em Ciências Sociais da Universidade Federal do Maranhão (PPGCSOC/UFMA). E-mail: rodrigofolhes@yahoo.com.br

OLIVEIRA, Ana Caroline Amorim; ARAÚJO, Daisy Damasceno; CORRÊA, Katia Núbia Ferreira; FOLHES, Rodrigo Theophilo. Estratégias de visibilidade em contexto pandêmico: o mapeamento da pandemia da Covid-19 entre povos indígenas no Maranhão. Espaço Ameríndio, Porto Alegre, v. 15, n. 2, p. 98-118, mai./ago. 2021.
} 
Espaço Ameríndio

the new coronavirus on the lives of these peoples and on the reality of healthcare provided to them. The research has a qualitative approach, presenting the results of the mapping carried out from May to August 2020 and the methodological strategies caused by the pandemic context for the development of research in digital media (MILLER, 2020). We used four sources of statistical information for data collection as a basis: epidemiological bulletins produced at the federal, state and municipal levels, and information provided by indigenous and indigenous organizations, on their respective websites. We initially identified a lack of information about Covid-19 cases among indigenous peoples in official sources and, when published, did not include the specifics of people affected by the virus, presenting generic and generalized data, preventing us from understanding the health reality in a specific way. and differentiated. Thus, the pandemic spread in indigenous territories and the government's strategies contributed to this situation.

KEYSWORDS: covid-19 pandemic, methodological strategies, indigenous peoples, Maranhão. 


\section{Introdução}

No dia 28 de fevereiro de 2020 foram notificados os primeiros casos de suspeita do novo coronavírus Sars-CoV-2 no estado do Maranhão, Brasil. A partir do dia 17 de março de 2020 os casos suspeitos começam a se multiplicar. De 25 passam para 72 , no dia seguinte, e para 205 , no dia 19 de março. O primeiro registro de contaminação pela Covid19 no estado aconteceu no dia 20 de março de 2020 .

O mês de abril de 2020 inaugura a publicação sistemática dos boletins epidemiológicos do governo do estado a partir do diálogo com as Secretarias Municipais de Saúde. A Secretaria Estadual de Saúde passou a divulgar o número de casos gerais por municípios, incluindo informações como o número de contaminados, descartados, suspeitos, óbitos, dentre outros dados estatísticos. A essa altura nos perguntávamos: mas, e os números da Covid-19 entre povos indígenas no Maranhão? Estes números não apareciam nos boletins de saúde oficiais e essa invisibilidade é, justamente, o ponto de partida dos dados e análises aqui apresentados.

O primeiro registro de casos de contaminação pela Covid-19 entre povos indígenas no Maranhão, apresentado pela Secretaria Especial de Saúde Indígena (SESAI) e pelo Distrito Sanitário Especial Indígena do estado (DSEl-MA), ocorreu no dia 13 de maio de 2020. A partir de então se inicia o rápido avanço da contaminação pelo novo coronavírus entre os indígenas, elevando o Maranhão ao patamar negativo de epicentro da pandemia da Covid-19 entre povos indígenas no Brasil no dia 06 de julho do mesmo ano.

A metodologia adotada pela SESAI/DSEI-MA para informar a situação epidemiológica dos números da Covid-19 entre os povos indígenas no Brasil e, especificamente no Maranhão, além de mapear somente os dados dos povos ditos "aldeados" ${ }^{5}$, ocultava/oculta quais eram os povos que estavam sendo contaminados pelo novo coronavírus. Em seus "Informes Epidemiológicos" o órgão de saúde indígena fazia referência à contaminação entre indígenas no estado, mas sem especificar povo e/ou território de pertencimento.

A mesma rota metodológica seguia/segue a Secretaria Estadual de Saúde e algumas das secretarias municipais para informar o número de indígenas contaminados pela Covid-19, demarcando a falta de articulação/comunicação entre a SESAl e as respectivas secretarias. Estas últimas, apesar de não apresentarem os povos, especificamente, se referem aos casos da Covid-19 entre indígenas a partir de termos genéricos como "Aldeias", "Áreas indígenas" e, muito raramente, "Terras Indígenas".

\footnotetext{
${ }^{5}$ Neste contexto pandêmico foi retomado um discurso por parte do órgão indigenista oficial, a FUNAI, que afirma uma pretensa distinção entre indígenas, "aldeados" e indígenas, "não aldeados" ou "indígenas urbanos", na qual os primeiros seriam indígenas "verdadeiros" e, portanto, prioritários no atendimento à saúde, enquanto que os sem territórios demarcados ou vivendo em cidades seriam "menos indígenas". Esta é uma nova roupagem para um discurso colonial e racista que precisa ser contestado e superado, como aponta Schettino (2020).

OLIVEIRA, Ana Caroline Amorim; ARAÚJO, Daisy Damasceno; CORRÊA, Katia Núbia Ferreira; FOLHES, Rodrigo Theophilo. Estratégias de visibilidade em contexto pandêmico: o mapeamento da pandemia da Covid-19 entre povos indígenas no Maranhão. Espaço Ameríndio, Porto Alegre, v. 15, n. 2, p. 98-118, mai./ago. 2021.
} 
É nesse "rastro" deixado pelas secretarias e a partir da invisibilidade velada da SESAI que nos debruçamos para mapear, analisar e visibilizar os dados da Covid-19 entre povos indígenas no Maranhão, buscando compreender o grau de vulnerabilidade dos mesmos e a situação epidemiológica diante do cenário pandêmico. Os povos originários são afetados pelas epidemias e pandemias desde o processo de invasão colonial dos europeus que não se encerrou com o fim da colonização em termos históricos, como nos traz Ribeiro (1986) e Monteiro (2001). A vulnerabilidade biológica destes povos é conhecida historicamente e, na maioria das vezes, invisibilizada e desconsiderada na atualidade ${ }^{6}$.

Foi partindo do princípio da invisibilidade dos dados da Covid-19 entre os povos indígenas no estado, na tentativa de entender a situação sanitária desses povos frente à pandemia e monitorar a expansão dos casos de Covid-19 entre eles, que surge o Projeto Rede (CO) $\mathrm{Vida}^{7} \mathrm{de}$ mapeamento da Covid-1 9 entre povos indígenas no Maranhão 8 . Os dados mapeados pela Rede (CO) Vida de maio a agosto de 2020 resultaram na divulgação de sete (7) boletins epidemiológicos ${ }^{9}$, seis (6) mapas $^{10}$ e ensaios diversos sobre a situação sanitária dos povos indígenas no estado. A partir destes dados, buscamos construir diálogos e reflexões acerca dos impactos da pandemia entre os povos indígenas no Maranhão e das dificuldades de coleta de dados neste contexto de isolamento social. Desafios que refletem diretamente no exercício da pesquisa e na análise socioantropológica dos dados.

A partir de uma pesquisa descritiva-qualitativa expressa, especialmente, no formato de boletins epidemiológicos, os dados foram coletados através das redes sociais e em diálogo virtual com indígenas, parceiros de nossos trabalhos de pesquisa e ação, que, devido ao contexto pandêmico, nos impossibilitou de realizar o trabalho de campo de forma presencial. Desta forma, nossas fontes foram os sítios eletrônicos e as redes sociais (Instagram, Facebook e WhatsApp). Ao analisar essas informações on-line em diálogo com as comunidades indígenas através dos recursos eletrônicos, a pesquisa possibilitou um outro olhar para a construção do trabalho antropológico "tradicional", enriquecendo nossas experiências metodológicas. Desta forma, compreendemos essas experiências a partir do diálogo com Miller (2020)

\footnotetext{
${ }^{6}$ Os povos indígenas desde a invasão pelos europeus são acometidos por epidemias que adentraram o século XXI. Para ver a linha do tempo das epidemias entre os povos indígenas acesse: https://covid19.socioambiental.org/ Acesso em 31 de maio de 2021.

${ }^{7}$ O Projeto Rede (CO) Vida de mapeamento da Covid-19 entre povos indígenas no Maranhão é composto pelos quatro autores desse artigo, que compõem o Coletivo Mururu. As produções da Rede (CO)Vida estão disponíveis no sítio eletrônico: https://www.redecovida2020.com/home e na rede social Instagram: @rede.covida.

8 Registramos casos da Covid-19 entre os povos Tentehar/Guajajara, Awá-Guajá, Ka'apor, Gavião/Pukobyê, Ramkokamekra/Canela, Apaniekra/Canela, Krikati, Tremembé da Raposa, Tremembé do Engenho e Akroá Gamella.

${ }^{9}$ Os boletins datam de 31 de maio, 10 de junho, 21 de junho, 29 de junho, 09 de julho, 29 de julho e 17 de agosto de 2020. Disponíveis em: https://www.redecovida2020.com/boletim-epidemiologico-1 Acesso em 31 de maio de 2021 .

${ }^{10}$ Os mapas são de 23 e 30 de maio, 10 de junho (2 mapas), 21 de junho e 09 de julho de 2020. Disponíveis em: https://www.redecovida2020.com/mapas Acesso em 31 de maio de 2021.

OLIVEIRA, Ana Caroline Amorim; ARAÚJO, Daisy Damasceno; CORRÊA, Katia Núbia Ferreira; FOLHES, Rodrigo Theophilo. Estratégias de visibilidade em contexto pandêmico: o mapeamento da pandemia da Covid-19 entre povos indígenas no Maranhão. Espaço Ameríndio, Porto Alegre, v. 15, n. 2, p. 98-118, mai./ago. 2021.
} 
ao afirmar que situações de pesquisa on-line ou off-line não precisam ser entendidas como distintas, pois se trata de relações de sociabilidade que estão sendo criadas e experienciadas pelos envolvidos.

Os dados da Covid-19 entre povos indígenas no Maranhão foram consultados nos sítios eletrônicos das prefeituras municipais, do governo do estado do Maranhão, Ministério da Saúde e Secretaria Especial de Saúde Indígena (SESAI), e, principalmente, nos perfis oficiais nas redes sociais das respectivas prefeituras e secretarias (estadual e municipais). Esses dados foram acrescidos e confrontados com outros disponibilizados pelos órgãos indigenistas da sociedade civil e organizações indígenas, a exemplo dos dados disponibilizados pelo Conselho Indigenista Missionário (CIMI) e Comitê Estatístico do Maranhão. Um ponto essencial foi a comunicação direta com membros dos diversos povos indígenas buscando articular as informações e relatos das comunidades com os dados das instituições indigenistas.

Assim, este artigo objetiva apresentar o mapeamento da Covid-19 entre os povos indígenas no estado do Maranhão, refletindo sobre os impactos do novo coronavírus na vida destes povos e sobre a realidade de assistência à saúde destinada a eles. O texto está estruturado da seguinte forma: no primeiro momento uma análise do mapeamento dos dados e as estratégias metodológicas realizadas no contexto da pandemia para a construção dos dados epidemiológicos; em seguida, refletimos sobre como o DSEI-MA se torna o epicentro da Covid-19 no país. Por fim, as considerações finais.

Registro dos números da COVID-19 entre povos indígenas no Maranhão e estratégias de mapeamento e visibilidade: um desafio à qualificação dos dados.

Oficialmente, existem no estado do Maranhão nove povos indígenas com territórios demarcados. São eles: Awá Guajá, Canela/Apaniekra, Canela/Ramkokamekra, Gavião/Pukobyê, Ka'apor, Krenyê, Krepumkateyê, Krikati e Tentehar/Guajajara. Os povos que estão em processo de retomada ou levante, como eles denominam, são os Akroá Gamella, Anapuru Muypurá, Kariú-Kariri, Tremembé da Raposa, Tremembé do Engenho e Tupinambá. A distribuição dos povos indígenas no estado do Maranhão está representada no mapa abaixo. 
Imagem 1 - Mapa de distribuição dos povos indígenas no Maranhão.

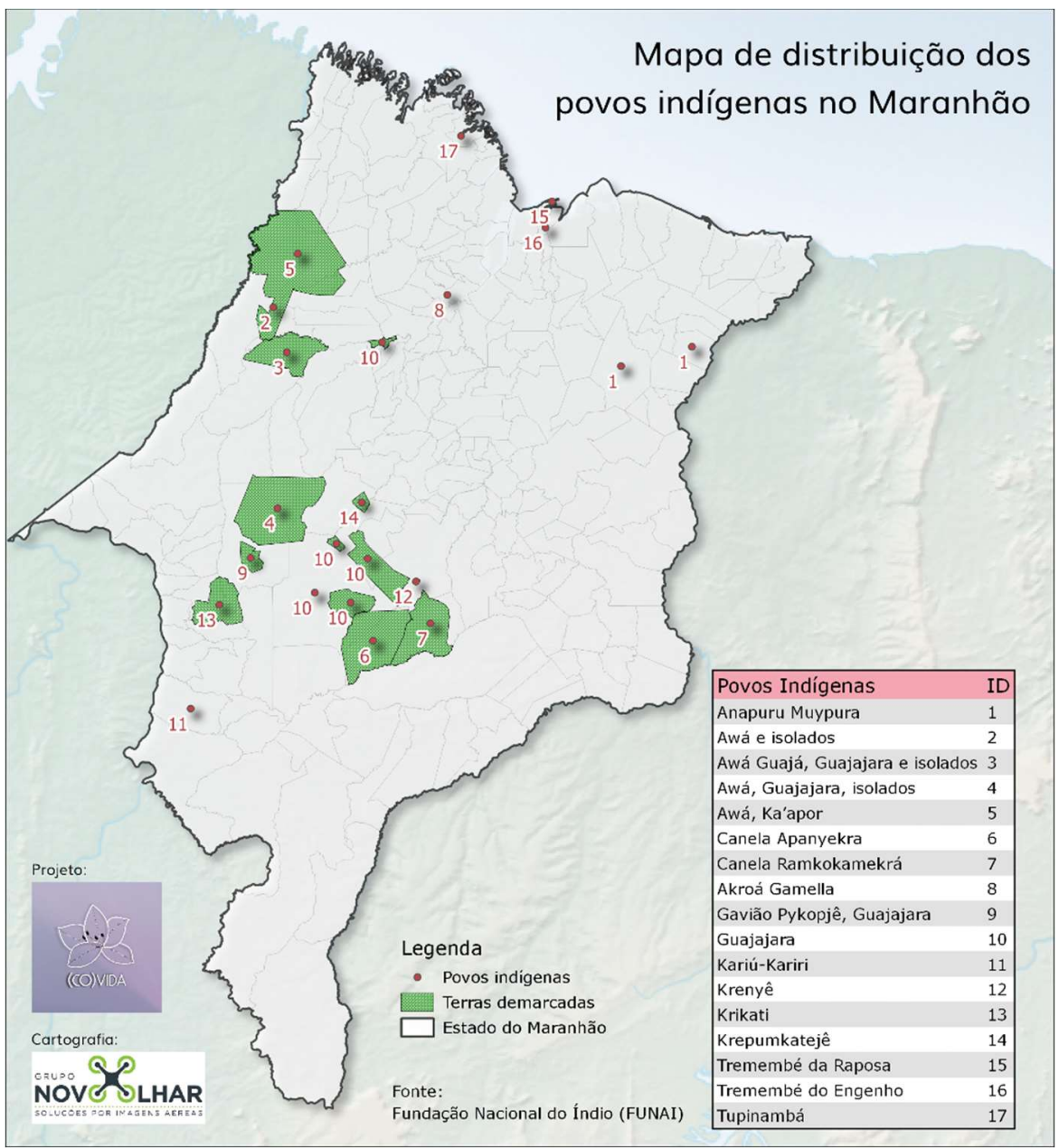

Elaboração: Cartografia Novo Olhar e Rede (CO) Vida/Coletivo Mururu. Fonte: FUNAI e Rede (CO) Vida/Coletivo Mururu.

Da totalidade de duzentos e dezessete (217) municípios no estado, trinta e sete (37) deles incidem em territórios indígenas, demarcados e não demarcados (IBGE, 2010). Os boletins desses municípios foram as nossas fontes iniciais da coleta de dados sobre a Covid-19 entre os indígenas no Maranhão, partindo do pressuposto inicial de invisibilidade dos dados por parte da Secretaria de Saúde do estado e da SESAI/DSEIMA.

As bases cartográficas do Instituto Brasileiro de Geografia e Estatística (IBGE) e da Fundação Nacional do Índio (FUNAI) nos ajudaram no processo de visualização dos municípios que incidem sobre os territórios indígenas no estado. Os primeiros mapas que divulgamos apresentavam os dados gerais da Covid-19 em alguns destes municípios. Através dos mapas era possível observar pelas cores a proporção de casos notificados do novo coronavírus em cada um dos municípios. À medida que o número de casos de Covid-19 nessas áreas crescia, as chances de contágio nos territórios indígenas eram potencializadas. A visualização 
regional desses dados epidêmicos nos ajudaram a ter uma dimensão do impacto da Covid-19 entre os povos que habitam naqueles espaços, cada vez que os números aumentavam nos municípios.

Como a SESAI/DSEI-MA registrava os dados da Covid-19 pelo número geral de casos desconsiderando os povos, territórios e aldeias, encontramos nos boletins das secretarias municipais um aporte, ainda que frágil, para compreender quem eram os povos que estavam sendo contaminados pelo novo coronavírus. A ideia de aporte frágil se deve ao fato dos referidos boletins também não citarem os povos contaminados, apenas apresentarem termos indicativos de registros dos casos entre indígenas: "aldeia", "área indígena", e, apenas um município, Amarante do Maranhão, registrava os casos a partir das "Terras Indígenas" (TIs).

Tendo como referência os municípios, procuramos qualificar os dados a partir das informações primárias coletadas. No início da sistematização começamos mapeando um total de vinte e nove (29) municípios que incidem sobre territórios indígenas. Posteriormente, aumentamos esse número para trinta e um (31) e depois trinta e três (33) municípios, à medida que ampliamos nossas pesquisas acerca dos povos indígenas do estado, consultando informações em diferentes bancos de dados. Quatro (04) municípios "ficaram de fora desse mapeamento inicial, por se referirem a territórios em disputa por povos em processo de retomada ou levante, acerca dos quais tínhamos poucas informações.

Em nosso primeiro boletim, de 31 de maio de 2020, apresentamos dados gerais da Covid-19 em vinte e nove (29) municípios, com dados do número de "suspeitos", "notificados", "confirmados", "monitorados", "recuperados", "óbitos" e "descartados"'. Realizamos o mapeamento nos respectivos sítios eletrônicos e perfis das prefeituras nas redes sociais e identificamos que somente seis (06) dos vinte e nove (29) municípios fizeram referência a casos de contaminação entre povos indígenas: Amarante do Maranhão, Arame, Bom Jardim, Grajaú, Montes Altos e Sítio Novo. Em nenhum deles constava o povo que estava sendo contaminado pelo novo coronavírus.

O município de Amarante do Maranhão, conforme afirmamos acima, apresentou em seus boletins epidemiológicos, desde o início, os dados por TI, com registros nas Tls Arariboia (07) e Governador (06), totalizando treze (13) casos nas duas Tls. O município de Arame apresentou os casos confirmados da Covid-19 entre indígenas a partir da categoria genérica "área indígena", com vinte e três (23) casos confirmados. O município de Bom Jardim também seguiu o percurso da caracterização genérica a partir do termo "aldeia", com vinte (20) casos

\footnotetext{
${ }^{11}$ Os municípios de Brejo, Chapadinha, Cururupu e Estreito possuem territórios em disputa pelos povos Anapuru Muypurá, Tupinambá e Kariú-Kariri. Tais povos estão em processo de luta pelo reconhecimento étnico e territorial pelo Estado, cujos preceitos legais se traduzem, para eles, como "levante" ou "retomada". Em janeiro de 2021 foi lançada uma carta aberta destes povos exigindo seu direito à vacinação como grupos prioritários e em maio de 2021 saiu uma segunda carta denunciando ainda a vulnerabilidade sanitária que estes povos estão vivenciando no contexto pandêmico, exigindo celeridade e prioridade na vacinação. Disponível em: https://cimi.org.br/2021/02/povos-pressionam-e-governo-do-maranhao-estendevacinacao-aos-indigenas-que-moram-nas-cidades/. Acesso em 31 de maio de 2021.

${ }^{12}$ Esses são termos padronizados pelo Ministério da Saúde, SESAI e secretarias estadual e municipais. OLIVEIRA, Ana Caroline Amorim; ARAÚJO, Daisy Damasceno; CORRÊA, Katia Núbia Ferreira; FOLHES, Rodrigo Theophilo. Estratégias de visibilidade em contexto pandêmico: o mapeamento da pandemia da Covid-19 entre povos indígenas no Maranhão. Espaço Ameríndio, Porto Alegre, v. 15, n. 2, p. 98-118, mai./ago. 2021.
} 
confirmados entre indígenas. Os municípios de Grajaú, Montes Altos e Sítio Novo apresentaram os dados trazendo o nome das aldeias onde foram registrados os casos confirmados: Aldeia Aramy (01), município de Grajaú, Aldeia São José (01) e Aldeia Campo Alegre (04), município de Montes Altos, totalizando cinco (05) casos, e Aldeia Nova Jerusalém (27), município de Sítio Novo. Ao todo, identificamos oitenta e nove (89) casos da Covid-19 entre indígenas em seis (06) municípios.

À medida que o novo coronavírus vai avançando sobre as populações indígenas, o número de municípios que apresentam casos de contaminação entre indígenas também se apresenta em uma linha crescente. De seis (06) municípios registrados no nosso primeiro boletim, cuja data base é o dia 31 de maio de 2020, mais três municípios registram casos da Covid-19 entre povos indígenas durante todo o mês de junho. São eles: Barra do Corda, Fernando Falcão e Jenipapo dos Vieiras. A partir dos dados do nosso segundo boletim epidemiológico, divulgado em 10 de junho de 2020, os três novos municípios seguem a mesma configuração de apresentar os povos indígenas em seus boletins epidemiológicos a partir das aldeias onde os casos de Covid-19 são registrados.

Nos dados atualizados até o dia 10 de junho, os números de casos da Covid-19 entre indígenas crescem de forma expressiva, com exceção de Sítio Novo, que mantém o mesmo número de casos por um longo período: Amarante (17), Arame (70), Bom Jardim (34), Grajaú (12), Montes Altos (11) e Sítio Novo (27). Os três novos municípios notificaram os seguintes números: Barra do Corda (01), Fernando Falcão (31) e Jenipapo dos Vieiras (87), totalizando duzentos e noventa (290) casos da Covid-19 entre indígenas, em nove (09) municípios. Duzentos e um (201) casos a mais do que o boletim divulgado dez (10) dias antes.

Sem ainda podermos entrar nas causas que levaram ao aumento significativo de casos nesse intervalo de 10 dias, é preciso destacar que, por um lado, do ponto de vista estatístico, as secretarias municipais começaram a notificar os registros da Covid-19 entre os povos indígenas do município e, por outro, houve mais testagens nas aldeias, como nos foi informado pelos indígenas. Para tanto, o crescimento de número de casos pode ter se dado não só pela proliferação do vírus, mas, sobretudo, pelo esforço, um pouco maior, em detectar e registrar publicamente os casos.

Com a multiplicação significativa dos casos de contágio e de transmissão, os primeiros casos de óbitos confirmados e suspeitos acenderam o sinal de alerta nas aldeias. Quando o número de casos confirmados se aproxima perigosamente do número de casos infectados e de baixa cura clínica, dá-se no Maranhão o primeiro caso de óbito registrado pelo DSEI-MA. Apesar de ter registrado o primeiro óbito entre indígenas no boletim da SESAI do dia 04 de junho de 2020, o DSEI-MA não registra qual povo foi acometido por essa perda.

Até aquele momento tínhamos mapeado e publicado na rede social Instagram do Projeto Rede (CO) Vida dois óbitos na Terra Indígena Rio Pindaré, povo Tentehar/Guajajara, identificados através da rede de 
contatos com lideranças indígenas no estado. No dia 03 de junho notificamos o primeiro óbito de uma liderança feminina de sessenta e sete (67) anos, que teria acontecido dia 31 de maio de 2020. No dia 04 de junho notificamos o falecimento de uma anciã de noventa e oito (98) anos.

Outras redes de mapeamento nacional da Covid-19 entre povos indígenas, realizado por organizações indígenas e indigenistas, apontaram um caso de óbito entre o povo Krikati e outro caso que eles qualificam como "não identificado". No entanto, não conseguimos dados mais precisos sobre essa informação. Quanto ao povo Krikati, entramos em contato com indígenas da aldeia São José, TI Krikati, e os mesmos negaram a existência de óbitos por Covid-19 entre seu povo. Importante frisar que os municípios não identificam óbitos indígenas em seus boletins. Estes são registrados de forma generalizada, sem identificação étnica. É possível identificar nos boletins de alguns municípios o registro de casos confirmados. Entretanto, não se consegue acompanhar o quadro de evolução da doença entre indígenas.

No terceiro boletim, de 21 de junho de 2020, começamos apresentando os dados da Covid-19 entre indígenas registrados pela SESAI/DSEI-MA, que entre o dia 13 de maio (primeiro registro) e 22 de junho $^{13}$ (data que tomamos como base de análise) registrou quatrocentos e quarenta e nove (449) casos, um aumento gradativo significativo. Os boletins epidemiológicos da SESAI coadunam com a invisibilização dos povos indígenas, citando números brutos, seguindo uma estrutura de diálogo entre variáveis epidemiológicas e números de casos para cada variável. A partir deles não se consegue dizer o nome do povo, a qual Terra Indígena ele pertence, aldeia, etc. Em contrapartida, os casos registrados pelos municípios, se não seguem os princípios étnicos dos povos indígenas existentes no Maranhão, pelos menos apresentam indícios de onde buscar esses dados por povos, pois permite que busquemos a partir do dado "aldeia" e "Tls", quais são os povos que estão sendo atingidos pela Covid-19.

Essas informações genéricas e omissas quanto a diversidade dos povos indígenas no Maranhão nos conduziu à necessidade de dar visibilidade aos povos que estavam sendo acometidos pelo novo coronavírus. Seguindo este percurso metodológico começamos a construir dados cada vez mais qualitativos acerca dos povos acometidos pela Covid-19 no estado, discriminando os povos localizados nos limites territoriais dos municípios que registram casos em seus boletins, bem como a qual polo-base do DSEI-MA os mesmos são vinculados administrativamente.

Neste terceiro boletim de 21 de junho de 2020, permaneceu o número de nove (09) municípios que registraram casos da Covid-19 entre indígenas em seus boletins epidemiológicos e o número de casos registrados foi de quinhentos e trinta e cinco (535). Com o mapeamento

\footnotetext{
${ }^{13}$ Os boletins epidemiológicos da SESAI eram divulgados todos os dias, exceto aos domingos. Por isso não alinhamos a data base de consulta do boletim SESAI com a data base do nosso terceiro boletim, em virtude de que o dia 21 de junho de 2020 foi um domingo.

OLIVEIRA, Ana Caroline Amorim; ARAÚJO, Daisy Damasceno; CORRÊA, Katia Núbia Ferreira; FOLHES, Rodrigo Theophilo. Estratégias de visibilidade em contexto pandêmico: o mapeamento da pandemia da Covid-19 entre povos indígenas no Maranhão. Espaço Ameríndio, Porto Alegre, v. 15, n. 2, p. 98-118, mai./ago. 2021.
} 
Espaço Ameríndio

e qualificação dos dados, identificamos que o povo indígena mais atingido pela pandemia no Maranhão é o povo Tentehar/Guajajara e uma das interpretações possíveis é o fato de possuírem a maior população indígena no estado, além de estarem distribuídos em mais de 10 terras indígenas demarcadas (residindo, ainda, em terras de outros povos). Os números da Covid-19 entre os Tentehar/Guajajara permaneceram elevados até o último boletim epidemiológico, conforme podemos visualizar no gráfico abaixo ${ }^{14}$.

Imagem 2 - Gráfico: Casos confirmados da Covid-19 por povo indígena no Maranhão.

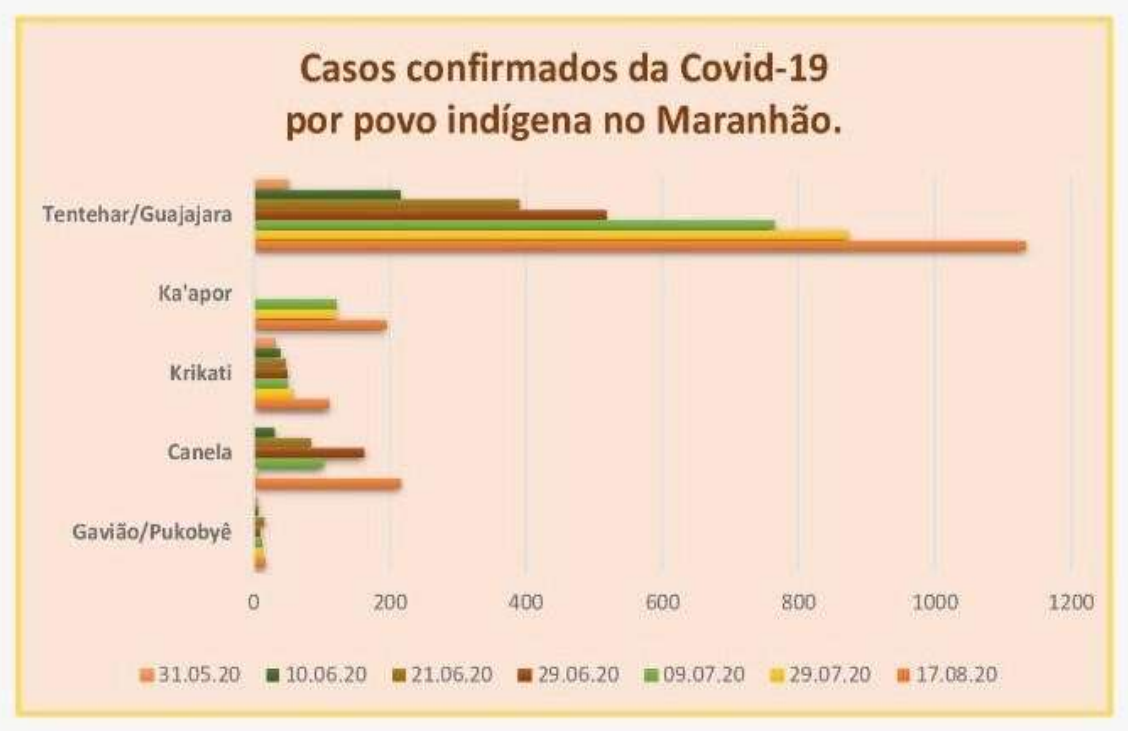

Elaboração: Rede (CO) Vida/Coletivo Mururu.

Fonte: Boletins Epidemiológicos das SEMUS e Comitê Estatístico, 2020.

Entre os dias 31 de maio e 10 de junho de 2020, tivemos um aumento de $225 \%$ no número de casos confirmados, de oitenta e nove (89) para duzentos e noventa (290) registros. Entre os dias 10 e 21 de junho de 2020, um aumento percentual de $84,48 \%$, duzentos e quarenta e cinco (245) novos casos em onze dias.

Em nosso quarto boletim, de 29 de junho de 2020, mapeamos setecentos e trinta e oito (738) casos. Isso representa duzentos e três (203) casos a mais do que o monitoramento de 21 de junho de 2020, que fora de quinhentos e trinta e cinco (535) casos. Um aumento de $38 \%$ dos casos confirmados em uma semana.

\footnotetext{
${ }^{14}$ O gráfico não apresenta números da Covid-19 entre os Tremembé (da Raposa e do Engenho) e entre os Akroá Gamella, visto que esses números não compuseram nossos boletins de maio a agosto de 2020, mas apareceram separadamente em ensaio publicado no site da Rede (Co)Vida e na rede social Instagram em 22 de agosto de 2020, intitulado "A situação sanitária dos povos indígenas Tremembé (da Raposa e do Engenho) e Akroá Gamella frente à pandemia da Covid-19.”. Os números são: Tremembé da Raposa - 06 suspeitos e 10 recuperados; Tremembé do Engenho - 06 suspeitos e 01 confirmado; e Gamella - 30 suspeitos, 38 confirmados e 01 óbito. O gráfico não apresenta, ainda, os números da Covid-19 entre os Awá Guajá. Em junho de 2020 tivemos a informação de que uma família de indígenas do povo Awá Guajá (um casal e o filho recém-nascido) teria sido contaminada na CASAI-São Luís em maio de 2020.

OLIVEIRA, Ana Caroline Amorim; ARAÚJO, Daisy Damasceno; CORRÊA, Katia Núbia Ferreira; FOLHES, Rodrigo Theophilo. Estratégias de visibilidade em contexto pandêmico: o mapeamento da pandemia da Covid-19 entre povos indígenas no Maranhão. Espaço Ameríndio, Porto Alegre, v. 15, n. 2, p. 98-118, mai./ago. 2021.
} 
No boletim do dia 29 de junho realizamos o cruzamento das aldeias informadas nos boletins dos municípios às suas respectivas Terras Indígenas. Estabelecemos os seguintes critérios: terra indígena, povo indígena, SEMUS, polo base do DSEI-MA, município de referência (atendimento secundário de saúde), localidades (TIs, aldeias, área indígena) e total de casos. Assim, fomos conseguindo identificar os povos indígenas, apontando os territórios contaminados pelo novo coronavírus e desconsiderando a noção de índio genérico veiculado nos boletins consultados.

Novos povos indígenas foram sendo contaminados pelo novo coronavírus com o aumento de casos confirmados. Até o dia 09 de julho de 2020 , data do nosso quinto boletim, já se contabilizava um total de mil e quarenta e nove (1049) casos. Ampliava-se, ainda, o número de municípios que apresentaram casos de Covid-19 entre indígenas, aumentando de nove (09) para onze (11), com a inclusão dos municípios de Centro do Guilherme e Maranhãozinho. Estes municípios também não registravam o nome do povo acometido ${ }^{15}$. O primeiro utilizava a categoria "indígenas" para contabilizar os números e o segundo trazia o nome da aldeia que registrou os casos. Neste boletim incluímos em nossa tabulação e qualificação dos dados o número de óbitos por povo, TI, SEMUS e localidades, totalizando cinco (05) óbitos ${ }^{16}$, que já haviam sido registrados no perfil da Rede (CO) Vida na rede social Instagram.

No boletim do dia 29 de julho de 2020 conseguimos ampliar e qualificar os dados sobre os óbitos, iniciados no boletim anterior. Neste boletim, o número de casos contaminados ampliou-se para mil e sessenta e oito (1.068). Uma das nossas principais fontes para a construção dos dados dos óbitos de forma mais precisa, além do número de contaminados, foi o Comitê Estatístico do Maranhão ${ }^{17}$, formado por organizações indígenas e indigenistas. Em nosso boletim de 17 de agosto de 2020, registramos, segundo as SEMUS, mil cento e dois casos (1.102). O gráfico abaixo nos permite visualizar a evolução dos casos da Covid-19 entre indígenas nos sete (07) boletins.

\footnotetext{
${ }^{15}$ Os dois municípios registram a presença de indígenas do povo Ka’apor.

16 Todos os cinco (05) óbitos registrados entre os Tentehar/Guajajara.

${ }^{17}$ Inicialmente, a denominação era Comitê "Estático" do Maranhão sendo alterado para Comitê Estatístico do Maranhão. Pouco tempo depois o Comitê se desfez em razão da dificuldade de continuar o trabalho de tabulação dos dados devido à extensão dos mesmos. Esta foi a explicação que alguns dos membros nos relataram.
}

OLIVEIRA, Ana Caroline Amorim; ARAÚJO, Daisy Damasceno; CORRÊA, Katia Núbia Ferreira; FOLHES, Rodrigo Theophilo. Estratégias de visibilidade em contexto pandêmico: o mapeamento da pandemia da Covid-19 entre povos indígenas no Maranhão. Espaço Ameríndio, Porto Alegre, v. 15, n. 2, p. 98-118, mai./ago. 2021. 
Espaço Ameríndio

Imagem 3 - Gráfico: Evolução dos casos da Covid-19 entre povos indígenas no Maranhão.

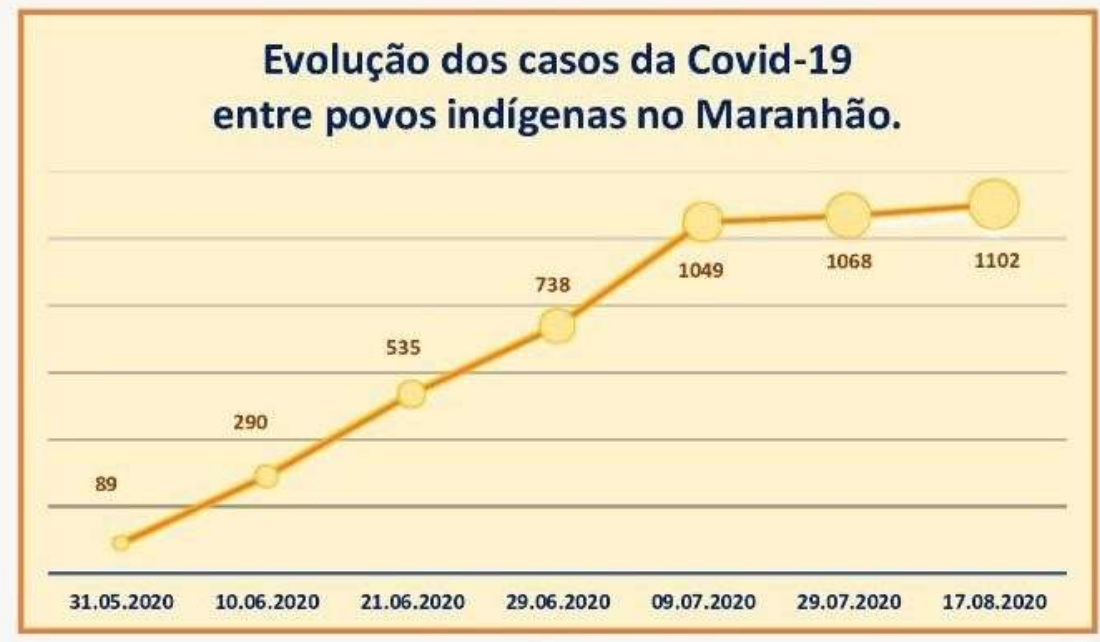

Elaboração: Rede (CO) Vida/Coletivo Mururu.

Fonte: Boletins Epidemiológicos das SEMUS, 2020.

No boletim de 17 de agosto de 2020 registramos os números de casos a partir de três fontes de informações estatísticas sobre a Covid-19 entre indígenas: SEMUS (com data base em 17/08), Comitê Estatístico do Maranhão (data base 03/08) e SESAI/DSEI-MA (data base 17/08), com os registros, respectivamente, de mil cento e dois (1.102), mil quatrocentos e setenta e sete (1.477) e mil trezentos e setenta (1.370) casos da Covid19 entre povos indígenas no Maranhão. Podemos perceber que há uma incongruência nos dados, conforme tabela abaixo.

Imagem 4 - Quadro: Casos da Covid-19 entre povos indígenas no Maranhão.

\begin{tabular}{|c|c|c|}
\hline \multicolumn{3}{|c|}{ CASOS DA COVID-19 ENTRE POVOS INDÍGENAS NO MARANHÃO } \\
\hline $\begin{array}{c}\text { SEMUS } \\
(17 / 08 / 20)\end{array}$ & $\begin{array}{c}\text { COMITÊ ESTATÍSTICO } \\
(03 / 08 / 20)\end{array}$ & $\begin{array}{c}\text { DSEI-MA/SESAI } \\
(17 / 08 / 20)\end{array}$ \\
\hline 1.102 & 1477 & 1.370 \\
\hline
\end{tabular}

\author{
Elaboração: Rede (CO) Vida/Coletivo Mururu. \\ Fonte: Boletins Epidemiológicos das SEMUS, \\ Comitê Estatístico do Maranhão e DSEI-MA/SESAI, 2020.
}

Cabe ressaltar que o número de óbitos aumentou para trinta e nove (39), conforme quadro abaixo, enquanto a SESAI/DSEI-MA registrou apenas vinte e cinco (25), uma diferença de 14 óbitos. Destacamos, ainda, quanto ao registro dos óbitos, que continuamos em constante diálogo com os povos indígenas, especialmente, os Tentehar/Guajajara e os Krikati. 
Imagem 5 - Quadro: Óbitos por Covid-19 entre povos indígenas no Maranhão.

\begin{tabular}{|c|c|c|}
\hline \multirow{2}{*}{ ÓBITOS POR COVID-19 ENTRE POVOS INDÍGENAS NO MARANHÃo } \\
(Agosto/2020) \\
\hline \multirow{2}{*}{ Povo } & Terra Indígena & $\begin{array}{c}\text { Quantitativo de } \\
\text { óbitos }\end{array}$ \\
\cline { 2 - 3 } & & Total: 39 \\
\hline \multirow{2}{*}{ TENTEHAR/GUAJAJARA } & Arariboia & 11 \\
\cline { 2 - 3 } & Bacurizinho/Morro Branco & $\mathbf{0 2}$ \\
\cline { 2 - 3 } & Canabrava/Guajajara & 12 \\
\cline { 2 - 3 } & Rio Pindaré & 05 \\
\hline KA'APOR & Alto Turiaçu & 03 \\
\hline CANELA & Kanela & 01 \\
\hline KRIKATI & Krikati & 04 \\
\hline AKROÁ GAMELLA & Sem território demarcado & 01 \\
\hline
\end{tabular}

Elaboração: Rede (CO) Vida/Coletivo Mururu.

Fonte: Comitê Estatístico do Maranhão e Rede (CO) Vida/Coletivo Mururu., 2020.

Os Tremembé (da Raposa e do Engenho), localizados no município de Raposa e de São José de Ribamar, na Grande São Luís, e os Akroá Gamella, localizados nos municípios de Penalva, Viana e Matinha, não apareciam nos boletins das secretarias de saúde dos respectivos municípios nos quais estão em processo de levante e luta por demarcação de seus territórios. A partir do Comitê Estatístico eles passam a ser incorporados no mapeamento sanitário do estado. Fizemos uma publicação específica sobre a situação sanitária desses povos, a pedido das próprias lideranças indígenas, no dia 22 de agosto de 2020, onde registramos dez (10) casos recuperados entre os Tremembé do Raposa, um (01) caso confirmado entre os Tremembé do Engenho e trinta e oito (38) confirmados entre os Akroá Gamella, este último com o registro de um (01) óbito.

A publicização dos dados da Covid-19 a cada boletim epidemiológico publicado pela Rede (CO) Vida reiterava a urgência de uma política indigenista de enfrentamento da questão sanitária vivida pelos povos indígenas, que conduziram o estado do Maranhão ao lugar de epicentro dos casos da Covid-19 entre indígenas. Tal situação será analisada no tópico a seguir. 
Espaço Ameríndio

\section{Maranhão em evidência na Amazônia Legal: o epicentro dos casos da Covid- 19 entre povos indígenas.}

O Brasil possui dentro de seu território trinta e quatro (34) DSEls, que se constituem como unidades gestoras descentralizadas do Subsistema de Atenção à Saúde Indígena (SASISUS). Esses distritos são divididos por critérios territoriais e tem por base a ocupação geográfica das comunidades indígenas (PNASPI, 2002).

No Maranhão, o DSEl, como os demais no Brasil, conta com a estrutura de polos base, os quais são as primeiras referências das equipes multidisciplinares de saúde indígena que atuam nas aldeias, além das Casas de Saúde Indígena (CASAl). São seis (6) polos bases e duas (2) CASAIS que prestam atendimento de saúde aos povos indígenas no referido estado.

Como já referenciado anteriormente, o Maranhão avançou gradativamente nos casos de contaminação e de óbitos pelo novo coronavírus. Somente de casos confirmados, temos uma alta no período em que publicamos o primeiro boletim, com dados até 31 de maio de 2020, de 89 casos para 1.102 casos, em nosso último boletim do dia 17 de agosto do mesmo ano ${ }^{18}$. Um quadro evolutivo significativo em termos numéricos. São um mil e treze (1.013) casos a mais, em quase três meses de mapeamento e monitoramento, mesmo diante do processo de subnotificação e silenciamento dos casos indígenas pelo governo federal e seu respectivo órgão indigenista de saúde.

Esse quadro evolutivo da situação epidemiológica dos povos indígenas que colocou o Maranhão como epicentro dos casos da Covid19 entre os povos indígenas da Amazônia Legal, no período de 06 a 17 de julho de 2020, com um mil cento e dezoito (1.118) casos (COIAB, 2021), pode ter sido potencializado por diversos motivos, entre eles, o crescimento exponencial das invasões das Terras Indígenas. Por exemplo, na TI Arariboia, segundo dados do Instituto Socioambiental (ISA), o desmatamento acumulado até julho de 2019 consumiu 22.902,85 hectares de floresta. E, em relação aos meses de março e julho de 2020, durante a pandemia da Covid-19, o desmatamento detectado foi de 47,64 de hectares, representando um aumento de desmatamento de $36 \%$, somente nesse período pandêmico. ${ }^{19}$

Os municípios que possuem em sua área a maior porcentagem da TI Arariboia são Amarante do Maranhão e Arame, com respectivamente $83,35 \%$ e $7,27 \%$ de área ocupada. Tais municípios, desde o início do mapeamento de casos da Covid-19 entre os indígenas pela Rede (CO) Vida, apresentaram um alto índice de contaminação pelo vírus entre seus habitantes. Os dois primeiros boletins, de 31 de maio e 10 de junho de 2020, mapeiam esses dados e demonstram o grau de contaminação entre os munícipes não indígenas. Em Amarante do Maranhão, registramos

\footnotetext{
18 Tomando como base os dados das Secretarias Municipais de Saúde (SEMUS).

${ }^{19}$ Disponível em https://www.socioambiental.org/pt-br/noticias-socioambientais/desmatamento-e-covid19-explodem-em-terras-indigenas-mais-invadidas-da-amazonia. Acessso em: 31 de maio de 2021

OLIVEIRA, Ana Caroline Amorim; ARAÚJO, Daisy Damasceno; CORRÊA, Katia Núbia Ferreira; FOLHES, Rodrigo Theophilo. Estratégias de visibilidade em contexto pandêmico: o mapeamento da pandemia da Covid-19 entre povos indígenas no Maranhão. Espaço Ameríndio, Porto Alegre, v. 15, n. 2, p. 98-118, mai./ago. 2021.
} 
Espaço Ameríndio

duzentos e trinta e três (233) e trezentos e cinquenta e oito (358) casos confirmados do novo coronavírus, respectivamente. Um aumento de cento e vinte e cinco (125) casos em menos de 01 (um) mês de mapeamento. No caso do município de Arame, o número de casos de contaminação evolui de noventa e três (93) para duzentos e um (201) nesse mesmo período. Um aumento de cento e oito (108) casos.

Dos seis (06) municípios ${ }^{20}$ que incidem sobre a TI Arariboia, somente Amarante do Maranhão e Arame contabilizam em seus boletins epidemiológicos casos confirmados da Covid-19 entre indígenas. Mesmo com a ausência de informação dos outros municípios sobre os indígenas contaminados, a referida $\mathrm{TI}$ apresenta até o registro do último boletim de 17 de agosto de 2020, duzentos e trinta e três (233) casos da Covid-19.

Se levarmos em conta a situação de invasão e desmatamento da referida $\mathrm{TI}$ por madeireiros e caçadores que queimam as florestas, intimidam e matam lideranças indígenas, afugentam as caças e burlam as barreiras sanitárias, é possível comparar que o aumento de números de casos de contaminação por Covid-19 entre a população não indígena incide diretamente sobre a população indígena da TI Arariboia. De acordo com os já citados boletins da Rede (CO) Vida (de 31.05 a 10.06.20), Amarante passou de sete (7) casos da Covid-19 entre indígenas para onze (11) e Arame teve um aumento de quarenta e sete (47) casos, passou de vinte e três (23) para setenta (70) casos entre os indígenas.

Situação semelhante de invasão acontece com a TI Krikati. Essa é uma TI homologada desde 2004, mas que ainda está invadida por não indígenas, tanto aqueles considerados como posseiros de boa-fé que ainda não foram indenizados pelos órgãos competentes pelas suas benfeitorias no território, como aqueles considerados como de má-fé, que, por lei, são desprovidos desse direito de indenização. No total, até o ano de 2014, a FUNAI contabilizava 224 famílias inseridas nessas duas situações jurídicas.

Neste ano de 2021 , os Krikati, com suas diversas lideranças, apresentaram um vídeo-manifesto ${ }^{21}$ no Acampamento Terra Livre (ATL), no qual chamam a atenção para a não regularização do seu território há mais de 20 anos após a homologação. Ressaltam, ainda, que a pandemia da Covid-1 9 e a falta de fiscalização fomentou a entrada de mais invasores e o retorno daqueles que já tinham sido indenizados pela FUNAI. No vídeo apontam para a preocupação com a "plantação de lavouras e construção de áreas de pastagens" no território, contribuindo sobremaneira para a degradação do mesmo.

No caso da TI Krikati, o município que possui em sua área a maior porcentagem desse território é Montes Altos. São 58,78\% de área ocupada, segundo dados do Instituto Socioambiental/ISA ${ }^{22}$. Nos dois

\footnotetext{
${ }^{20}$ Amarante do Maranhão, Arame, Bom Jesus das Selvas, Buriticupu, Grajaú e Santa Luzia (ISA, 2021).

${ }^{21}$ Disponível em:

https://www.youtube.com/watch?v=rs1i9E4KNgc\&list=PLchh9Eb_8lo5w_FwCMzetTPRyyXbA8oj3\&in $\mathrm{dex}=65 \& \mathrm{ab}$ channel=APIBOFICIAL Acesso em 31 de maio de 2021.

${ }^{22}$ Disponível em https://www.socioambiental.org/pt-br/noticias-socioambientais/desmatamento-e-covid19-explodem-em-terras-indigenas-mais-invadidas-da-amazonia . Acessado em: 31 de maio de 2021

OLIVEIRA, Ana Caroline Amorim; ARAÚJO, Daisy Damasceno; CORRÊA, Katia Núbia Ferreira; FOLHES, Rodrigo Theophilo. Estratégias de visibilidade em contexto pandêmico: o mapeamento da pandemia da Covid-19 entre povos indígenas no Maranhão. Espaço Ameríndio, Porto Alegre, v. 15, n. 2, p. 98-118, mai./ago. 2021.
} 
boletins citados acima o número de casos confirmados da Covid-1 9 entre não indígenas no município foi de trinta e seis (36) para setenta e cinco (75) casos. Um aumento de trinta e nove (39) casos, ou seja, mais de $100 \%$ no período analisado.

Os casos de contaminação entre não indígenas no município têm grandes chances de incidir diretamente nos casos de contaminação de indígenas da TI Krikati. A TI fica somente a 20 minutos de carro da sede do município. Os Krikati vivem em constante deslocamento para o município a fim de comprar alimentos para sua sobrevivência física, uma vez que a segurança alimentar desses povos tem sido, paulatinamente, prejudicada pela invasão de seu território - seja por grandes projetos de infraestrutura, cujas medidas para minimizar impactos fez, pelo contrário, potencializá-los, seja pelas invasões de toda sorte de interesses: religiosos, políticos e econômicos. Portanto, para além da sobrevivência física atrelada à compra de alimentos, as cidades do entorno se tornaram referências para a resolução de políticas indígenas e indigenistas, para o lazer, para cultos, bem como para o recebimento de benefícios sociais por parte do poder público.

Um exemplo dessa correlação entre a expropriação da autonomia política e territorial, a dependência da estrutura municipal e o aumento dos números de casos da Covid-19 entre indígenas pode ser observado em Montes Altos. Nesse município, no mesmo período que aumentou o número de casos de contaminação pelo novo coronavírus entre os não indígenas, também aumentou o número de casos entre indígenas das aldeias São José e Campo Alegre, situadas nos limites territoriais do município. O aumento foi de mais de $100 \%$, passando de cinco (05) para onze (11) casos.

Sobre a extrusão de invasores, tendo em vista que a permanência deles nas Tls estaria agravando o contágio dos indígenas pela Covid-19, a Arguição de Descumprimento de Preceito Fundamental - ADPF ${ }^{23}$ 709/MC/DF reivindica um Plano Geral de Enfrentamento e Monitoramento da Covid-1 9 para Povos Indígenas. Exige do governo federal, entre outras coisas, um Plano de Isolamento de Invasores para impedir o contato de não indígenas com os indígenas.

O Ministro do STF, Luís Roberto Barroso, reconhece em sua decisão que é imperativa a "remoção de (terceiros não autorizados)". Reconhece também que a presença de invasores em terras indígenas "constitui violação do direito de tais povos ao seu território, cultura e crença, a sua vida e saúde" (ADPF 709/2021). Decide, então, pela elaboração e implementação de um "plano de isolamento de invasores" como foi demandado pela ADPF em pauta. Entretanto, o que se observou em contato e conversa com os indígenas deste estado é que muitas das barreiras sanitárias que possibilitariam esse isolamento nasceram de uma ação praticada pelos próprios indígenas, sem o apoio do governo federal.

\footnotetext{
${ }^{23}$ Ela funciona como uma ação de controle concentrado de constitucionalidade trazida pela Constituição Federal de 1988.

OLIVEIRA, Ana Caroline Amorim; ARAÚJO, Daisy Damasceno; CORRÊA, Katia Núbia Ferreira; FOLHES, Rodrigo Theophilo. Estratégias de visibilidade em contexto pandêmico: o mapeamento da pandemia da Covid-19 entre povos indígenas no Maranhão. Espaço Ameríndio, Porto Alegre, v. 15, n. 2, p. 98-118, mai./ago. 2021.
} 
Espaço Ameríndio

As situações evidenciadas acima demonstram que o governo federal não é somente omisso. Ele também contribui para a proliferação do vírus entre os povos indígenas quando não impede a invasão das TIs, ou seja, não garante os direitos territoriais indígenas violando os preceitos constitucionais que determina o artigo 231 :

São reconhecidos aos índios sua organização social, costumes, línguas, crenças e tradições, e os direitos originários sobre as terras que tradicionalmente ocupam, competindo à União demarcá-las, proteger e fazer respeitar todos os seus bens (BRASIL, 1988).

Ou ainda, quando se trata da posse e usufruto exclusivo dos índios ao seu território no parágrafo 2, do referido artigo: "As terras tradicionalmente ocupadas pelos índios destinam-se a sua posse permanente, cabendo-Ihes o usufruto exclusivo das riquezas do solo, dos rios e dos lagos nelas existentes" (BRASIL, 1988).

O desinteresse do governo federal em implementar as barreiras sanitárias nas Terras Indígenas ajudou a disseminação rápida e ativa do coronavírus, a despeito dos cuidados sanitários adotados pelos próprios indígenas.

Ao procurar mapear os dados de contaminação por Covid-19 dos indígenas do Maranhão frente a outros estados da Amazônia Legal, traçamos a posição do DSEI-Maranhão em relação à evolução do vírus de acordo com os boletins da Coordenação das Organizações Indígenas da Amazônia (COIAB), retratando principalmente os casos confirmados. ${ }^{24}$

Os primeiros números registrados pela COIAB, relativos ao DSEI-MA em suas redes sociais - Instagram, Twitter e Facebook -, apontam que o Maranhão já é uma referência em números elevados de casos confirmados em relação aos outros 25 (vinte e cinco) DSEls existentes no território brasileiro. Foram sessenta e oito (68) casos no dia 28 de maio de 2020 , ocupando o terceiro $\left(3^{\circ}\right)$ lugar em números de casos confirmados. Logo em seguida, na data de 31 de maio de 2020, ocupa o quarto (4º lugar, com um número de setenta e seis (76) casos e no dia 02 de junho de 2020 cai para a quinta ( $5^{\mathrm{a}}$ ) posição, com 90 casos. Em seguida, no dia 05 de junho de 2020, o número de casos confirmados aumenta para cento e vinte (120) e o DSEI-MA volta a ocupar o terceiro $\left(3^{\circ}\right)$ lugar.

Entre os dias 07, 09, 12 e 14 de junho de 2020, o DSEI-MA transita entre o terceiro $\left(3^{\circ}\right)$ e o quarto $\left(4^{\circ}\right)$ lugar nos dados registrados pela COIAB, com os respectivos números de casos confirmados: 131, 131, 200 e 216. Até então, o DSEl Alto Rio Solimões é considerado o epicentro dos casos confirmados da Covid-19 entre os povos indígenas, desde os primeiros informativos da COIAB, com números que variam entre trezentos a quase quinhentos casos $(219,351,407,441,448,493,495)$

\footnotetext{
${ }^{24}$ A COIAB trabalha com os dados de 25 DSEIs que estão localizados dentro da Amazônia Legal. Ela faz a disposição dos DSEIs por maior número de casos de contaminação somente até a quinta $\left(5^{a}\right)$ posição em ordem decrescente. Os dados levantados apresentam números maiores que os apresentados pela SESAI, porque para além deste dado do órgão oficial, ela se utiliza de dados informados pelas lideranças indígenas, pelos profissionais de saúde indígena e organizações da Rede COIAB.

OLIVEIRA, Ana Caroline Amorim; ARAÚJO, Daisy Damasceno; CORRÊA, Katia Núbia Ferreira; FOLHES, Rodrigo Theophilo. Estratégias de visibilidade em contexto pandêmico: o mapeamento da pandemia da Covid-19 entre povos indígenas no Maranhão. Espaço Ameríndio, Porto Alegre, v. 15, n. 2, p. 98-118, mai./ago. 2021.
} 
nos períodos de 28 de abril a 14 de junho de 2020. Outros DSEls que apresentam altos índices de casos confirmados são: Manaus/AM, Guamá Tocantins/PA, Amapá e Norte do Pará/AP, e Alto Rio Negro/AM.

Entre os dias 18 e 30 de junho de 2020, os casos confirmados no DSEI-MA disparam de forma significativa a ponto de, entre os Distritos, ele ocupar o segundo $\left(2^{\circ}\right)$ lugar com os respectivos números de casos confirmados: 380, 443, 466, 509, 543 e 654. No dia 03 de julho de 2020, a COIAB registra em seu informe que o DSEI-MA apresenta um total de setecentos e setenta e sete (777) casos confirmados da Covid-19. O Maranhão, nessa data, está com nove (09) casos a menos do que o DSEI do Alto Rio Solimões, ainda o epicentro dos casos da Covid-19 entre os povos indígenas, com um número de setecentos e oitenta e seis (786) casos confirmados.

No dia 06 de julho de 2020, o DSEI-MA registra oitocentos e sessenta e oito (868) casos confirmados e assume o lugar de epicentro de casos da Covid-19 entre os povos indígenas no Brasil. Ele permanece nesse lugar até o dia 17 de julho - data do último monitoramento feito pela Rede (CO)Vida com os dados disponibilizados pelo sítio eletrônico da COIAB - com os seguintes números de casos confirmados: novecentos e quarenta e sete (947), em 09/07/20, mil e vinte e oito (1.028), em $14 / 07 / 20$ e mil cento e dezoito ( 1.118 ), em 17/07/20. Confira no gráfico abaixo a "reta" ascendente dos números de contaminados pelo coronavírus no Maranhão.

Imagem 6 - Gráfico: Número de casos confirmados da Covid-19 - DSEI/Maranhão.

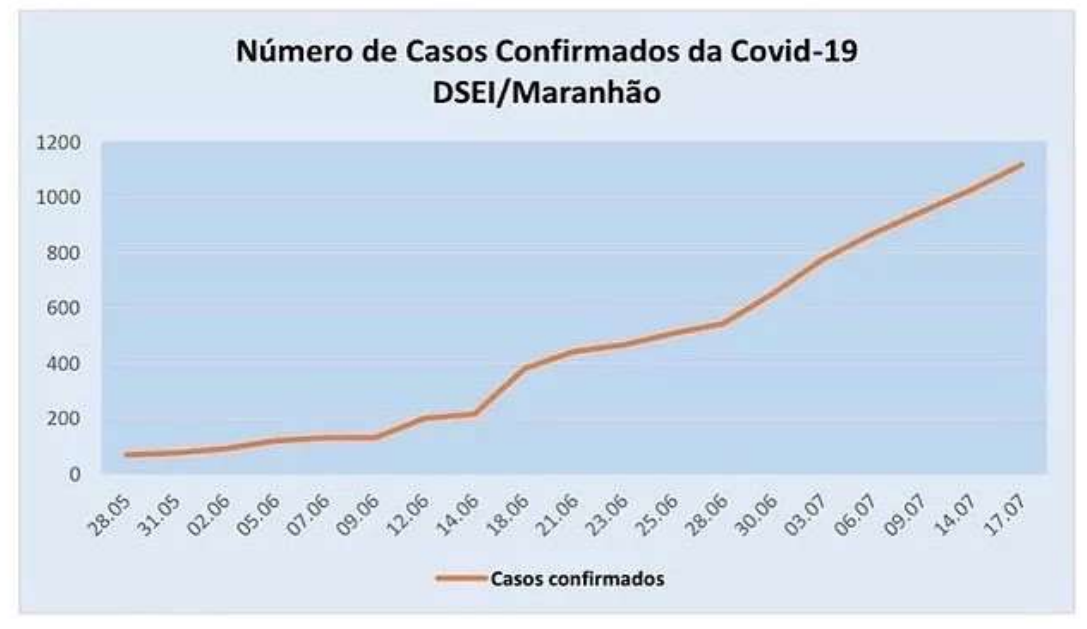

Elaboração: Rede (CO) Vida/Coletivo Mururu.

Fonte: COIAB - Coordenação das Organizações Indígenas

A velocidade com que os casos da Covid-19 impactaram os povos indígenas no Maranhão expõe a fragilidade da atual política indigenista de enfrentar o variado conjunto de problemas e dificuldades vividos no cotidiano dos povos indígenas, em especial, os da saúde indígena. Além 
Espaço Ameríndio

da demora em planejar e executar um plano emergencial federal com medidas eficazes de prevenção e combate à pandemia nos territórios indígenas, a SESAI, por meio do DSEI-MA, tem coagido os municípios a não divulgarem de forma detalhada os casos confirmados de indígenas em seus boletins epidemiológicos.

Essa situação de não divulgação dos dados foi potencializada a partir de setembro de 2020, no período das campanhas eleitorais para prefeito e vereador. À medida que as campanhas foram ganhando força nos municípios, os boletins municipais que vinham trazendo os dados de casos entre os indígenas foram deixando de ser publicizados. A justificativa dada pelos gestores das secretarias municipais de saúde para a ausência de dados foi que o DSEI-MA solicitou a suspensão da divulgação dos boletins epidemiológicos.

\section{Considerações finais}

Apesar de não contar com nenhum recurso financeiro para a realização da pesquisa e de todos nós estarmos em isolamento social, o Coletivo Mururu, através do Projeto Rede (CO)Vida, se dispôs a investigar a pandemia da Covid-19 entre os povos indígenas no estado do Maranhão e de construir uma narrativa que pudesse lançar luz em duas frentes: 1) no entendimento de que para elaborar e executar políticas públicas se faz necessário ter dados mais consistentes sobre o problema que se quer atacar; 2) na expectativa de fornecer material de pesquisa para outros pesquisadores, dentre eles, os próprios indígenas que cada vez mais ocupam o espaço acadêmico.

Estamos, enquanto coletivo, aprendendo a mapear as realidades que são omitidas pelo governo federal e, também, por muitos gestores municipais. Esses últimos, seja pelo descaso histórico quanto ao tratamento às populações indígenas; seja pelo desconhecimento de suas responsabilidades para com os munícipes indígenas; seja pelo medo dos grupos locais em "perder" territórios para indígenas "falsificados"; seja pela falta de estrutura do poder público municipal; seja por aceitarem as orientações do governo federal, seja tudo isso junto.

Nunca caímos na esparrela de achar que o Sars-Cov-2, causador da Covid-19, seria uma "gripezinha". Pelo contrário, temíamos que mais uma epidemia fosse usada contra os povos indígenas, tal como ocorrera ao longo de todos esses séculos de invasão aos territórios indígenas. Nos dias de hoje, o negacionismo é o orientador das políticas do governo federal e encontra ressonância em vários setores da vida social no Maranhão e alhures. Continuaremos nossa tarefa de analisar os novos ciclos do coronavírus que, infelizmente, não cessarão enquanto o Brasil e o mundo não forem capazes de respeitar o nosso bem mais precioso, a vida. 
Espaço Ameríndio

\section{Referências bibliográficas}

BRASIL. Constituição (1988). Constituição da República Federativa do

Brasil. Brasília, DF: Centro Gráfico, 1988.

IBGE. Censo 2010. Disponível em: https://censo2010.ibge.gov.br/ Acesso em: 20 de maio de 2021.

ISA-Instituto Socioambiental. Terra Indígena Arariboia. Disponível em: https://terrasindigenas.org.br/pt-br/terras-indigenas/3600 Acesso em: 20 de maio de 2021.

ISA-Instituto Socioambiental. Terra Indígena Krikati. Disponível em: https://terrasindigenas.org.br/pt-br/terras-indigenas/3600 Acesso em: 20 de maio de 2021.

ISA-Instituto Socioambiental. Cataclismo Biológico - epidemias na história indígena. Disponível em: https://covid19.socioambiental.org/ Acesso em: 10 de julho de 2021.

MILLER, Daniel. Notas sobre a pandemia: como conduzir uma etnografia durante o isolamento social. Tradução: Camila Balsa e Juliane Bazzo. Disponível em: https://blogdolabemus.com/2020/05/23/notas-sobre-a-pandemia-como-conduzir-umaetnografia-durante-o-isolamento-social-por-daniel-miller/ Acesso em: 20 de maio de 2021.

MONTEIRO, John. Tupis, Tapuias e Historiadores: Estudos de História Indígena e do Indigenismo. Tese apresentada para concurso de livre docência. Campinas, Unicamp. 2001 .

PNASPI. Política Nacional de Atenção à Saúde dos Povos Indígenas. Brasília: Ministério da Saúde. Fundação Nacional de Saúde, 2002.

PAULA, Luís Roberto. ROSALEN, Juliana. Uma visualização da pandemia da Covid19 entre povos indígenas no Brasil a partir dos boletins epidemiológicos da SESAI. maio/2020.

Disponível

em: http://www.aba.abant.org.br/files/20200601_5ed561c92875e.pdf Acesso em 31 de maio de 2021.

REDE (CO)VIDA- Rede de Mapeamento da Covid-19 entre os povos indígenas no Maranhão. Disponível em: https://www.redecovida2020.com/home Acesso em $31 \mathrm{de}$ maio de 2021.

REDE (CO)VIDA- Rede de Mapeamento da Covid-19 entre os povos indígenas no Maranhão. Disponível em: @rede.covida. Acesso em 31 de maio de 2021.

RIBEIRO, Darcy. Os índios e a civilização: a integração das populações indígenas no Brasil Moderno. Petrópolis, Vozes: 1986. 
Espaço Ameríndio

SCHETTINO, Marcos Paulo Froés. Índios na cidade: a necessária superação da ideia de índios aldeados e desaldeados. In: Perícia em antropologia no MPF: primeiras contribuições no combate à pandemia da Covid-19. Brasília: MPF, 2021.

SUPREMO TRIBUNAL FEDERAL. Arguição de descumprimento de preceito fundamental 709 Distrito Federal. ADPF 709 / DF. Brasília, julh.2020.

Recebido em: 31/05/2021* Aprovado em: 09/07/2021 * Publicado em: 30/08/2021 